\title{
Comparative Study between Magnesium Sulphate Versus Dexmedetomedine as Additives to Levobupivacine in Ultra Sonographic Guided Supraclavicular Block in Patient Undergoing Forearm Surgeries
}

\author{
Ahmed Hamody Hassan, Ayman Mohamed Abdelkareem*
}

Department of Anesthesia, Faculty of Medicine, Sohag University, Egypt.

*Corresponding author: Ayman Mohamed Abdelkareem, Mobile: (+20) 01021330778, E-Mail: aymann8100@gmail.com

\begin{abstract} anesthetic in regional block (supra clavicular block).

\section{INTRODUCTION}

Recent years' postoperative pain has a great importance in all surgeries preventing the central, peripheral and immunological stress response to tissue injury ${ }^{(1)}$. The postoperative period requires all our experiences as this period of most severe, agonizing pain that requiring our attention. So our goal is to achieve control of pain to extend to postoperative period without any side effects ${ }^{(2)}$.
\end{abstract}

Background: Supraclavicular block provides alternative way to general anesthesia for upper limb surgeries. They produce complete muscular relaxation, maintaining hemodynamic stability intraoperatively and avoidance of the risks with general anesthesia. The most important target of anesthesia is to manage the patient's pain, as we can do the surgical procedures with no discomfort, and controlling of intraoperative and postoperative pain.

Objective: Our study aimed to detect how adding Mg sulphate or dexmedetomidine can improve the effect of local

Patient and Methods: 90 patients aged between 20-75 years old with ASA I- II who were scheduled for forearm surgeries under supraclavicular block anesthesia were enrolled in our study. This Study was conducted in Sohag University Hospitals from May 2019 to April 2020. Patients were divided into 3 equal groups.

Results: Magnesium sulphate had a more rapid onset of both sensory and motor block onset than dexmedetomedine and control groups. Dexmedetomidine had a longer duration of both motor and sensory block than magnesium sulphate group and control groups. Dexmedetomidine had a longer analgesic effect than magnesium sulphate group and control group. As regards rate of complications, there was no significant difference between the three groups. Conclusion: The addition of $1 \mathrm{ml}(100 \mu \mathrm{g})$ dexmedetomedine or $200 \mathrm{mg}$ magnesium sulphate to supraclavicularyinjected levobupivacaine improved the onset, duration and postoperative analgesia of levobupivacaine.

Keywords: Mg sulphate, Dexmedetomedine, Levobupivacine, Ultrasonographic guided, Supraclavicular block.

Various additive drugs as opioids, neostigmine, clonidine and hyaluronidase...etc have been added to local anaesthetics as adjuvants to make rapid onset, good quality, and to prolong the duration and post-operative analgesia ${ }^{(3)}$. Levobupivacaine is a long-acting local anaesthetic widely used in modern anaesthetic practice. It is well recognized that inadvertent i.v. injection or administration of toxic doses by another route can lead to severe central nervous system (CNS) toxicity and cardiovascular compromise ${ }^{(4)}$. Some authors said that the effects of opioids on regional blockade are controversial, as addition of opioids in brachial plexus block is reported to improve postoperative analgesia by one team, and another authors said that no effect was found ${ }^{(5)}$.

Dexmedetomidine has many uses as in intravenous regional anesthesia (Bier's block) (5) intravenous (i.v.) sedation and analgesia for intubation. Moreover, it facilitates putting the patients on mechanical ventilation in patients admitted to intensive care units (ICUs) ${ }^{(6)}$ and in minor operation in patients for surgical and other procedures not needing for intubation. In addition, it is recorded that it improves the quality of intrathecal and epidural anesthesia ${ }^{(7)}$. Its use for peripheral nerve blocks has newly observed, but its use in supraclavicular brachial plexus block is minimal ${ }^{(8)}$. In our study, we investigated whether adding dexmedetomidine to levobupivacaine for supraclavicular brachial plexus block would improve the sensory and motor blocks and duration of analgesia.

$\mathrm{Mg}$ sulphate is a mineral supplement given if magnesium level decreased in the blood. In addition, magnesium is very important for the normal function of cells, nerves, bones, muscles, and heart. So, we need a well-balanced diet to maintain normal blood levels of magnesium ${ }^{(9)}$. Some authors said that addition of magnesium sulfate to lidocaine leads to decreasing the postoperative pain and increasing the onset and duration of sensory and motor blocks in ultrasound guided supraclavicular brachial plexus block for upper limb surgeries ${ }^{\mathbf{( 1 0 )}}$.

Our aim of this study was to detect how adding $\mathrm{Mg}$ sulphate or dexmedetomidine improves the effect of local anesthetic in regional block (supra clavicular nerve block), and to compare the effect of their adding to levobupivacaine in postoperative pain management in sonar guided supraclavicular plexus block.

\section{PATIENTS AND METHODS}

A prospective randomized controlled study for 90 patients (ASA I-II) of both sex, aged 20-75 years old in the period from May 2019 to April 2020. They were scheduled for elective forearm surgeries under supraclavicular block in Sohag University Hospital. 
Exclusion criteria: Patient refusal, patient with significant neurological, psychiatric or neuromuscular disease, suspected coagulopathy, morbid obesity, known allergy to some medications (levobupivacine, $\mathrm{Mg}$ sulphate and dexmedetomidine), septicaemia and local infection at the block site.

90 patients were divided into 3 equal groups: Group (C) control group consisted of 30 patients received an ultrasound guided supraclavicular block using $25 \mathrm{ml}$ of $0.375 \%$ levobupivacaine, group (M): consisted of 30 patients received an ultrasound guided supraclavicular block using $25 \mathrm{ml}$ levobupivacaine $0.375 \%$ plus $200 \mathrm{mg} \mathrm{Mg}$ sulphate $20 \%$ and group (D) consisted of 30 patients received an ultrasound guided supraclavicular block using $25 \mathrm{ml}$ levobupivacaine $0.375 \%$ plus $1 \mathrm{ml}(100 \mu \mathrm{g})$ dexmedetomidine, after seeing investigations and examination of patients an 18 gauge iv cannula was inserted in non-operated upper limb and started lactated Ringer's solution at 5 $\mathrm{ml} / \mathrm{kg} / \mathrm{hr}$. All patients received $0.05 \mathrm{mg} / \mathrm{kg}$ medazolam intravenously 5 minutes before the procedure. The skin of the supraclavicular fossa was disinfected with a povidone-iodine solution of $10 \%$.

Patients were monitored for heart rate, NIBP and oxygen saturation. Patients also were observed for onset and duration of sensory and motor block in the post-anesthesia care unit (PACU). Patients were assessed for pain based on a visual analogue scale (VAS). Complications also were observed.

\section{Ethical approval and written informed consent: An approval of the study was obtained from Sohag University Academic and Ethical Committee. Every patient signed an informed written consent for acceptance of the operation.}

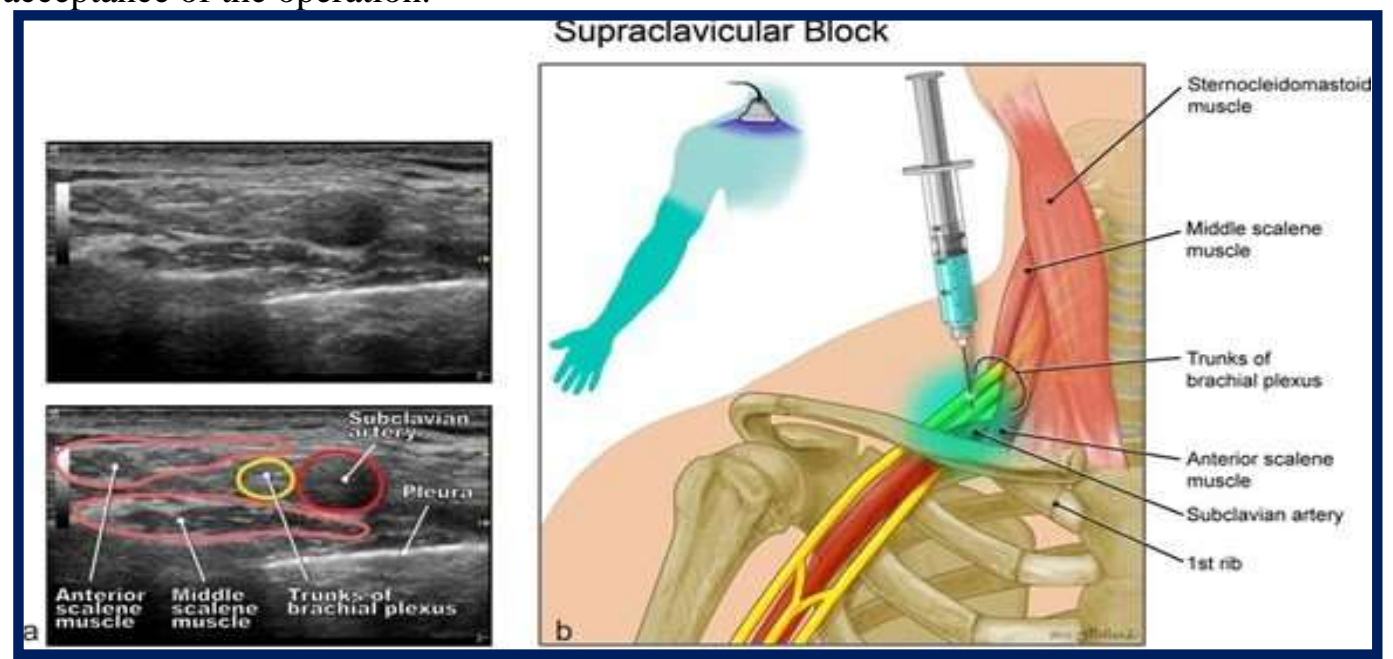

Figure (1): Supraclavicular brachial plexus block; a. Ultrasound image of the trunks of the brachial plexus sandwiched between the subclavian artery and the anterior and middle scalene muscles; $b$. Artist's depiction of the supraclavicular block illustrating proper needle and ultrasound probe positioning with a diagram of the upper limb representing the region that is successfully anesthetized using this approach ${ }^{(11)}$.

\section{Statistical analysis}

The collected data were coded, processed and analyzed using the SPSS (Statistical Package for Social Sciences version 22 for Windows ${ }^{\circledR}$ (IBM SPSS Inc, Chicago, IL, USA). Data were tested for normal distribution using the

\section{Ultrasound guided supraclavicular brachial plexus block:}

Position: After proper good positioning of the patient and under complete aseptic precautions, ultrasound guided supraclavicular brachial plexus block was performed.

The operator stood at either the head of the bed or facing the ipsilateral shoulder. The patient's head was turned to the other side between 30 and 45 away from the side to be blocked. After finishing skin established, noting the sternocleidomastoid muscles, clavicle and coronoid processes. A high-frequency linear probe was located in a coronal oblique axis by orienting the probe approximately parallel to the clavicle.

Technique: the Ultrasound examination started by locating the subclavian artery in the short axis view, where the artery was seen as a round pulsating, hypoechoic structure. At this moment, also the hyperechoic first rib underneath the artery and possibly, the pleura were seen. Lateral to the subclavian artery the anesthetist identifies the middle scalene, as it is characterized by its often-striated appearance. In-between the subclavian artery and middle scalene muscle the divisions of brachial plexus appear as hypoechoic grape-cluster-like structure. The block needle advances under constant visualization in an in-plane technique along the medial border of middle scalene, toward the lateral portion of the plexus. Here, a test dose shows spread of the local anesthestic in fascial layer surrounding the brachial plexus divisions. sterilization and the supraclavicular fossa was visually 
Shapiro Walk test. Qualitative data were represented as frequencies and relative percentages. Chi square test $(\chi 2)$ was used to calculate difference between two or more groups of qualitative variables. Quantitative data were expressed as mean \pm SD (Standard deviation). Independent samples t-test was used to compare between two independent groups of normally distributed variables (parametric data). $\mathrm{P}$ value $\leq 0.05$ was considered significant.

\section{RESULTS}

There was no statistically significant difference between the three study groups regarding age, sex, weight or duration of surgery (Table 1).

Table (1): Demographic characteristics of the studied groups

\begin{tabular}{|l|l|c|c|c|c|}
\hline \multicolumn{2}{|c|}{ Demographic variable } & Group $\mathbf{C ~} \mathbf{n = 3 0}$ & Group M n=30 & Group D n=30 & P-value \\
\hline Age in years & Mean \pm SD & $35.9 \pm 13.5$ & $38.6 \pm 12.3$ & $39.9 \pm 12.6$ & 0.606 \\
\hline \multirow{2}{*}{ Sex } & Male no (\%) & $13(65 \%)$ & $12(60 \%)$ & $14(70 \%)$ & 0.803 \\
\cline { 2 - 5 } & Female no (\%) & $7(35 \%)$ & $8(40 \%)$ & $6(30 \%)$ & \\
\hline Weight in kg & Mean \pm SD & $68.8 \pm 10.2$ & $71.7 \pm 9.8$ & $72.8 \pm 10.7$ & 0.459 \\
\hline $\begin{array}{l}\text { Duration of } \\
\text { surgery in hours }\end{array}$ & Mean \pm SD & $3.4 \pm 1.3$ & $3.45 \pm 1.3$ & $3.1 \pm 1.1$ & 0.647 \\
\hline
\end{tabular}

Regarding the onset of sensory block, there was no any statistically significant difference between the three groups $(P=0.052)$. Also, it was not significantly faster in group $C$ than group $D(P 2=0.051)$, and no significant difference between group $\mathrm{M}$ and group $\mathrm{D}(\mathrm{P} 3=0.125)$. Also, no statistical significant difference between group $\mathrm{M}$ and group $\mathrm{C}$ $(\mathrm{P} 1=0.055)$. As regards onset of motor block, there was no significant difference between the three study groups $(\mathrm{P}=$ $0.25)$. Besides, there was no significant difference between group $\mathrm{C}$ and $\mathrm{D}(\mathrm{P} 2=0.18) \&$ no-significant difference between group $\mathrm{C} \&$ group $\mathrm{M}(\mathrm{P} 3=0.07)$ (Table 2$)$.

Table (2): Onset of block (sensory and motor) of the three studied groups

\begin{tabular}{|l|c|c|c|c|c|c|c|}
\hline $\begin{array}{c}\text { Onset of } \\
\text { Sensory block } \\
\text { in minutes }\end{array}$ & $\begin{array}{c}\text { Group C } \\
\mathbf{n = 2 0}\end{array}$ & $\begin{array}{c}\text { Group } \\
\mathbf{M} \\
\mathbf{n = 2 0}\end{array}$ & $\begin{array}{c}\text { Group D } \\
\mathbf{n = 2 0}\end{array}$ & $\mathbf{P 1}$ & $\mathbf{P 2}$ & $\mathbf{P 3}$ & P \\
\hline Mean & 22.75 & 17.20 & 21.50 & 0.055 & 0.051 & 0.125 & 0.055 \\
\hline SD & 8.91 & 6.45 & 9.74 & & & & \\
\hline $\begin{array}{l}\text { Onset of } \\
\text { Motor block } \\
\text { in minutes }\end{array}$ & & & & & & & \\
\hline Mean & 22 & 19 & 21 & 0.43 & 0.18 & 0.07 & 0.25 \\
\hline SD & 7.25 & 5.86 & 7.97 & & & & \\
\hline
\end{tabular}

$\mathrm{P}: \mathrm{p}$ value for comparing between the three groups.

$\mathrm{p} 1: \mathrm{p}$ value for comparing between group $\mathrm{C}$ and group $\mathrm{M}$.

p2: $\mathrm{p}$ value for comparing between group $\mathrm{C}$ and group D. $\quad \mathrm{p} 3$ : $\mathrm{p}$ value for comparing between group $\mathrm{M}$ and group D.

${ }^{*}$ Statistically significant at $\mathrm{p} \leq 0.05\left({ }^{*}\right.$ mild, ${ }^{* *}$ moderate, ${ }^{* * *}$ highly $)$. ns: non-significant.

As regards duration of sensory block, there was a statistically significant difference between the three study groups $(\mathrm{p}=0.0001)$. It was mild significant longer in group $\mathrm{M}$ compared with group $\mathrm{C}(\mathrm{p} 1=0.01) \&$ but of moderate significance between group $\mathrm{M}$ with group $\mathrm{D}(\mathrm{P} 3=0.003$ both) and group $\mathrm{C}$ with group $\mathrm{D}(\mathrm{p} 2=0.0005)$. Concerning duration of motor block, there was significant difference between the three study groups $(\mathrm{P}=0.0001)$. Also, it was mild significantly longer in group $\mathrm{M}$ compared to group $\mathrm{C}(\mathrm{P} 1=0.01) \&$ more significant between group $\mathrm{C}$ and group $\mathrm{D}(\mathrm{P} 2=0.002)$. Moreover, there was significant difference between group $\mathrm{M}$ and group $\mathrm{D}(\mathrm{P} 3=0.03)$ (Table 3 ).

Table (3): Comparison Duration of block (sensory and motor) between the study groups

\begin{tabular}{|l|l|l|l|l|l|l|c|}
\hline & $\begin{array}{c}\text { Group C } \\
\mathbf{n = 2 0}\end{array}$ & $\begin{array}{c}\text { Group M } \\
\mathbf{n = 2 0}\end{array}$ & $\begin{array}{c}\text { Group D } \\
\mathbf{n = 2 0}\end{array}$ & P1 & P2 & P3 & P \\
\hline Mean & 5.30 & 7.90 & 9.20 & $0.01^{*}$ & $0.0005^{*}$ & 0.003 & $0.0001^{* *}$ \\
\hline $\begin{array}{l}\text { Sensory block } \\
\text { duration SD }\end{array}$ & 1.75 & 2.19 & 1.91 & \multicolumn{3}{|l}{} \\
\hline Mean & 5.90 & 8.50 & 9.80 & $0.01^{*}$ & $0.002^{*}$ & $0.03^{*}$ & $0.0001^{* *}$ \\
\hline $\begin{array}{l}\text { Motor block } \\
\text { duration SD }\end{array}$ & 1.37 & 2.33 & 1.933 & \multicolumn{5}{|l}{} \\
\cline { 2 - 5 }
\end{tabular}

$\mathrm{p}: \mathrm{p}$ value for comparing the three groups.

$\mathrm{p} 2$ : $\mathrm{p}$ value for comparing between group $\mathrm{C}$ and group $\mathrm{D}$

* Statistically significant at $\mathrm{p} \leq 0.05\left({ }^{*}\right.$ mild, ${ }^{* *}$ moderate, ${ }^{* * *}$ highly).

p3: $p$ value for comparing between group $M$ and group $D$

Regarding heart rate, there was no significant statistical difference between the studied three groups in first 6 hours of block. The difference became significant between group C and group M (P1) and also between Group D and group $\mathrm{C}$ (P3) after more than 6 hours of block. There was no significant difference between group M and group D (P2) along 
12 hours after block (Table 4).

Table (4): Comparison of heart rate between the three studied groups after block

\begin{tabular}{|c|c|c|c|c|c|c|c|}
\hline & Group C & Group M & \begin{tabular}{|l|} 
Group D \\
\end{tabular} & P1 & $\mathbf{P 2}$ & P3 & $\mathbf{P}$ \\
\hline \multirow[t]{2}{*}{ HR base line } & Mean 90 & 88 & 89 & \multirow[t]{2}{*}{0.12} & \multirow[t]{2}{*}{0.08} & \multirow[t]{2}{*}{0.07} & \multirow[t]{2}{*}{0.07} \\
\hline & SD 0.71 & 0.68 & 0.83 & & & & \\
\hline \multirow[t]{2}{*}{$30 \mathrm{~min}$} & Mean 85 & 84 & 85 & \multirow[t]{2}{*}{0.09} & \multirow[t]{2}{*}{0.041} & \multirow[t]{2}{*}{0.52} & \multirow[t]{2}{*}{0.064} \\
\hline & SD 1.1 & 1.4 & 0.9 & & & & \\
\hline \multirow[t]{2}{*}{$1 \mathrm{hr}$} & Mean 87 & 86 & 85 & \multirow[t]{2}{*}{0.058} & \multirow[t]{2}{*}{0.063} & \multirow[t]{2}{*}{0.37} & \multirow[t]{2}{*}{0.066} \\
\hline & SD 1.5 & 1.6 & 1.4 & & & & \\
\hline \multirow[t]{2}{*}{$3 \mathrm{hr}$} & Mean 88 & 87 & 86 & \multirow[t]{2}{*}{0.066} & \multirow[t]{2}{*}{0.069} & \multirow[t]{2}{*}{0.7} & \multirow[t]{2}{*}{0.07} \\
\hline & SD 2.1 & 1.8 & 1.65 & & & & \\
\hline \multirow[t]{2}{*}{$6 \mathrm{hr}$} & Mean 92 & 88 & 87 & \multirow[t]{2}{*}{0.056} & \multirow[t]{2}{*}{0.052} & \multirow[t]{2}{*}{0.45} & \multirow[t]{2}{*}{0.07} \\
\hline & SD 2.5 & 2.1 & 1.9 & & & & \\
\hline \multirow[t]{2}{*}{$12 \mathrm{hr}$} & Mean 94 & 90 & 90 & \multirow[t]{2}{*}{$0.049 *$} & \multirow[t]{2}{*}{$0.037 *$} & \multirow[t]{2}{*}{0.5} & \multirow[t]{2}{*}{$0.024^{*}$} \\
\hline & SD 1.9 & 1.7 & 1.85 & & & & \\
\hline
\end{tabular}

Regarding mean blood pressure, there was no significant statistical difference between the studied three groups (p) in first 6 hours. The difference became significant between group C and group M (P1) and also between group C and group D (P2). After more than 6 hours of block, there was no significant difference between group M and group D along (P3) 12 hours after block (Table 5).

Table (5): Comparison of mean blood pressure between the three studied groups after block

\begin{tabular}{|c|c|c|c|c|c|c|c|}
\hline & Group C & Group M & Group D & P1 & $\mathbf{P 2}$ & P3 & $\mathbf{P}$ \\
\hline \multirow[t]{2}{*}{ MBP base line } & Mean 90 & 92 & 89 & \multirow[t]{2}{*}{0.12} & \multirow[t]{2}{*}{0.24} & \multirow[t]{2}{*}{0.75} & \multirow[t]{2}{*}{0.5} \\
\hline & SD 0.14 & 0.15 & 0.138 & & & & \\
\hline \multirow[t]{2}{*}{$30 \mathrm{~min}$} & Mean 85 & 83 & 82 & \multirow[t]{2}{*}{0.095} & \multirow[t]{2}{*}{0.089} & \multirow[t]{2}{*}{0.56} & \multirow[t]{2}{*}{0.48} \\
\hline & SD 0.5 & 0.45 & 0.43 & & & & \\
\hline \multirow[t]{2}{*}{$1 \mathrm{hr}$} & Mean 84 & 82 & 80 & \multirow[t]{2}{*}{0.088} & \multirow[t]{2}{*}{0.076} & \multirow[t]{2}{*}{0.45} & \multirow[t]{2}{*}{0.68} \\
\hline & SD 1.1 & 0.85 & 0.89 & & & & \\
\hline \multirow[t]{2}{*}{$3 \mathrm{hr}$} & Mean 87 & 85 & 83 & \multirow[t]{2}{*}{0.075} & \multirow[t]{2}{*}{0.059} & \multirow[t]{2}{*}{0.7} & \multirow[t]{2}{*}{0.29} \\
\hline & SD 0.98 & 0.91 & 0.87 & & & & \\
\hline \multirow[t]{2}{*}{$6 \mathrm{hr}$} & Mean 87 & 84 & 82 & \multirow[t]{2}{*}{$0.045 *$} & \multirow[t]{2}{*}{$0.05^{*}$} & \multirow[t]{2}{*}{0.65} & \multirow[t]{2}{*}{0.06} \\
\hline & SD 0.85 & 0.80 & 0.81 & & & & \\
\hline \multirow[t]{2}{*}{$12 \mathrm{hr}$} & Mean 89 & 85 & 83 & \multirow[t]{2}{*}{$0.025^{*}$} & \multirow[t]{2}{*}{$0.017 *$} & \multirow[t]{2}{*}{0.75} & \multirow[t]{2}{*}{$0.05^{*}$} \\
\hline & SD 1 & 0.92 & 0.94 & & & & \\
\hline
\end{tabular}

$\mathrm{P}: \mathrm{p}$ value for comparing between the three groups. $\quad \mathrm{p} 1: \mathrm{p}$ value for comparing between group $\mathrm{C}$ and group $\mathrm{M}$.

$\mathrm{p} 2: \mathrm{p}$ value for comparing between group $\mathrm{C}$ and group $\mathrm{D}$. $\quad \mathrm{p} 3$ : $\mathrm{p}$ value for comparing between group $\mathrm{M}$ and group $\mathrm{D}$.

*Statistically significant at $\mathrm{p} \leq 0.05\left({ }^{*}\right.$ mild, ${ }^{* *}$ moderate, ${ }^{* * *}$ highly $)$

As regards first request analgesia given, there was a significant difference between the three study groups $(\mathrm{P}=$ $0.0001)$. It was highly significant smaller in group $\mathrm{D}$ compared to group $\mathrm{C}(\mathrm{P} 2=0.0001) \&$ compared with group $\mathrm{M}$ it was mildly significant smaller ( $\mathrm{P} 3=0.001$ ), while there was mild significant smaller in group $\mathrm{M}$ compared to group $\mathrm{C}$ $(\mathrm{P} 1=0.003)$ (Table 6).

Table (6): Comparison of first request for rescue analgesia among studied groups

\begin{tabular}{|c|c|c|c|c|}
\hline First analgesic request & Group C $(\mathbf{n = 2 0})$ & Group M $(\mathbf{n = 2 0})$ & Group D $(\mathbf{n}=\mathbf{2 0})$ & P-value \\
\hline $\mathbf{8} \mathbf{~ h r}$. & $5(25 \%)$ & $0(0 \%)$ & $0(0 \%)$ & $\mathrm{P}=0.0001^{* * *}$ \\
\hline $\mathbf{1 2} \mathbf{~ h r}$. & $10(50 \%)$ & $4(20 \%)$ & $0(0 \%)$ & $\mathrm{P} 1: 0.003^{* *}$ \\
\hline $\mathbf{1 8} \mathbf{~ h r}$. & $2(10 \%)$ & $7(35 \%)$ & $0(0 \%)$ & $\mathrm{P} 2: 0.0001 * * *$ \\
\hline $\mathbf{2 4} \mathbf{~ h r}$. & $0(0 \%)$ & $4(20 \%)$ & $5(25 \%)$ & $\mathrm{P} 3: 0.001 * *$ \\
\hline
\end{tabular}

P1: $\mathrm{p}$ value for Fisher exact test for comparing between group $\mathrm{C}$ and group $\mathrm{M}$.

P2: $\mathrm{p}$ value for Fisher exact test for comparing between group $\mathrm{C}$ and group D. $\quad$ P3: $p$ value Fisher exact test for comparing between group M and group D.

${ }^{*}$ Statistically significant at $\mathrm{p} \leq 0.05\left({ }^{*}\right.$ mild, ${ }^{* *}$ moderate, ${ }^{* * *}$ highly)

Regarding total analgesic dose postoperatively, there was a moderately significant difference between the three study groups $(\mathrm{P}=0.001)$. It was moderately significant smaller in group $\mathrm{D}$ compared to group $\mathrm{C}(\mathrm{P}=0.001) \&$ compared to group $\mathrm{M}$ it was mildly significant smaller $(\mathrm{P}=0.032)$. While there was mildly significant smaller in group $\mathrm{M}$ 
compared to group $\mathrm{C}(\mathrm{P}=0.031)$ (Table 7).

Table (7): Comparison of total analgesic dose postoperatively among three studied groups

\begin{tabular}{|c|c|c|c|c|}
\hline $\begin{array}{c}\text { Total analgesic Diclofenac } \\
\text { Na dose in mg }\end{array}$ & $\begin{array}{c}\text { Group C } \\
\mathbf{n = 2 0}\end{array}$ & Group M n=20 & $\begin{array}{c}\text { Group D } \\
\mathbf{n = 2 0}\end{array}$ & $\begin{array}{c}\text { P } \\
\text { value }\end{array}$ \\
\hline \multirow{2}{*}{ Mean \pm SD } & $176.47 \pm 52.6$ & $135.00 \pm 58.09$ & & $\mathrm{P}=0.001^{* *}$ \\
\cline { 4 - 5 } & & & $75 \pm 0.00$ & $\mathrm{P} 1: 0.031^{*}$ \\
\cline { 4 - 5 } & & & $\mathrm{P} 2: 0.001^{* *}$ \\
\hline
\end{tabular}

P: $p$ value for comparing he three studied groups.

$\mathrm{p} 1$ : $\mathrm{p}$ value for comparing between group $\mathrm{C}$ and group $\mathrm{M}$. $\mathrm{p} 2$ : $\mathrm{p}$ value for comparing between group $\mathrm{C}$ and group D. $\mathrm{p} 3$ : $\mathrm{p}$ value for comparing between group $\mathrm{M}$ and group D.

Postoperative pain assessment using Visual Analogue Scale (VAS) showed that when group C compared to base line, there was a highly significant increase in the VAS at $6 \mathrm{hrs}, 8 \mathrm{hrs}, 18 \mathrm{hrs}$ and $24 \mathrm{hrs}$ postoperative. Group (M): There was a statistically significant rise in VAS at 8 hours postoperatively and a strongly statistically significant increase at $18 \mathrm{hrs}$ and $24 \mathrm{hrs}$ postoperatively relative to the base line. Group D: There was a large rise in VAS at $18 \mathrm{hrs}$ and $24 \mathrm{hrs}$ postoperative relative to the base line. There was a statistically significant difference in VAS between the three groups studied at $8 \mathrm{hrs}, 12 \mathrm{hrs}$ and $18 \mathrm{hrs}$ postoperative and a mild statistically significant difference at $24 \mathrm{hrs}$ postoperative between the three groups studied. There was a statistically significant increase in VAS between the three groups examined at 8 hours postoperatively, a statistically significant increase at 12 hours postoperatively and a less significant increase at 18 hours postoperatively between group $\mathrm{C}$ and $\mathrm{M}$. Between group $\mathbf{C}$ and $\mathbf{M}$ : there was a significant difference in VAS between the three studied groups at $6 \mathrm{hrs}, 8 \mathrm{hrs}, 12 \mathrm{hrs}$ and $18 \mathrm{hrs}$ postoperative and a significant difference at $24 \mathrm{hrs}$ postoperative. Between group M, D: there was a significant difference in VAS between the three studied groups at $12 \mathrm{hrs}$ (Table 8).

Table (8): Comparison of VAS among the three studied groups

\begin{tabular}{|c|c|c|c|c|}
\hline \multirow{2}{*}{$\begin{array}{c}\text { Postoperative } \\
\text { period }\end{array}$} & \multicolumn{3}{|c|}{ Mean + SD } & \multirow[t]{2}{*}{ P-value } \\
\hline & Group C $(n=20)$ & Group M $(n=20)$ & Group D $(n=20)$ & \\
\hline $1 \mathrm{hr}$ & $\mathbf{0 . 0 0} \pm \mathbf{0}$ & $\mathbf{0 . 0 0} \pm \mathbf{0}$ & $\mathbf{0 . 0 0} \pm \mathbf{0}$ & 1.000 \\
\hline $2 \mathrm{hrs}$ & $0.00 \pm 0$ & $0.00 \pm 0$ & $0.00 \pm 0$ & 1.000 \\
\hline 4hrs & $0.05 \pm 0.22$ & $0.00 \pm 0$ & $0.00 \pm 0$ & 0.374 \\
\hline 6hrs & $0.95 \pm 0.82^{\# \# \#}$ & $0.00 \pm 0$ & $0.00 \pm 0$ & $<0.001 * * *$ \\
\hline 8hrs & $2.35 \pm 1.6$ & $0.65 \pm 1.04^{\#}$ & $0.10 \pm 0.44$ & $<0.001 * * *$ \\
\hline 12hrs & $4.35 \pm 1.9$ & $2.80 \pm 2.09$ & $0.65 \pm 1.04$ & $<0.001 * * *$ \\
\hline 18hrs & $4.80 \pm 2.2^{\# \# \#}$ & $3.60 \pm 1.7^{\# \# \#}$ & $1.55 \pm 1.14^{\# \# \# ~}$ & $<0.001 * * *$ \\
\hline 24hrs & $4.75 \pm 3.1^{\# \# \#}$ & $3.65 \pm 2.05^{\# \# \#}$ & $2.45 \pm 1.82^{\# \# \#}$ & 0.015* \\
\hline \multicolumn{5}{|c|}{ One way ANOVA test } \\
\hline & P1 & \multicolumn{2}{|c|}{$\mathbf{P 2}$} & P3 \\
\hline 1hr & 1.000 & \multicolumn{2}{|c|}{1.000} & 1.000 \\
\hline $2 \mathrm{hrs}$ & 1.000 & \multicolumn{2}{|c|}{1.000} & 1.000 \\
\hline 4hrs & 0.226 & \multicolumn{2}{|c|}{0.226} & 1.000 \\
\hline 6hrs & $<0.001 * * *$ & \multicolumn{2}{|c|}{$<0.001 * * *$} & 1.000 \\
\hline 8hrs & $<0.001 * * *$ & \multicolumn{2}{|c|}{$<0.001 * * *$} & 0.145 \\
\hline 12hrs & $0.008 * *$ & \multicolumn{2}{|c|}{$<0.001 * * *$} & $<0.001 * * *$ \\
\hline 18hrs & $0.037 *$ & \multicolumn{2}{|c|}{$<0.001 * * *$} & $0.001 * * *$ \\
\hline 24hrs & 0.155 & \multicolumn{2}{|c|}{$0.004 * *$} & 0.121 \\
\hline
\end{tabular}

p- value for one-way ANOVA test.

$\mathrm{p} 1: \mathrm{p}$ value for comparing between group $\mathrm{C}$ and group $\mathrm{M}$.

$\mathrm{p} 2$ : $\mathrm{p}$ value for comparing between group $\mathrm{C}$ and group $\mathrm{D}$. $\quad \mathrm{p} 3$ : $\mathrm{p}$ value for comparing between group $\mathrm{M}$ and group $\mathrm{D}$.

*Statistically significant at $\mathrm{p} \leq 0.05\left(*\right.$ mild, ${ }^{* *}$ moderate, $* * *$ highly $)$. n.s: non-significant.

\#: significant difference from basal value among each group individually at $<0.05$ (\#mild, \#\#moderate, \#\#\# highly).

\section{DISCUSSION}

In our study we found that $\mathrm{Mg}$ sulphate as an additive to local anesthetic made the onset of block faster (sensory block $17.20 \pm 6.45$ in min) (motor block $19 \pm$ $5.86 \mathrm{~min}$ ) than control group (sensory block $20.75 \pm 8.91$ min) (motor block $20 \pm 7.25$ ) who received local anesthetic only, while dexmedetomidine as an additive to local anesthetic made the onset of block slower (sensory block $21.50 \pm 9.74 \mathrm{~min}$ ) (motor block $21 \pm 7.97$ ) than control group but difference between the three groups is insignificant. Abdelfatah and Elshaer ${ }^{(12)}$ found in their studies that addition of Mg sulphate made the onset of block faster when it is added to lidocaine and epinephrine than to lidocaine and epinephrine only but no significant difference. In agreement with our study, Verma et al. ${ }^{(13)}$ also found in their study that $\mathrm{Mg}$ Sulphate as adjuvant in brachial plexus block made onset of block faster and it was dose-dependent when compared to other groups. In contrast to our study Haghighi et al. ${ }^{(14)}$ found in their study that adding $\mathrm{Mg}$ 
sulfate to lidocaine delayed the onset of block when it is compared to lidocaine alone to block the axillary plexus using the trans-arterial technique. Rao et al. ${ }^{(15)}$ in Andhra Pradesh, India, concluded in one study that the addition of magnesium sulfate to $0.5 \%$ bupivacaine in supraclavicular brachial plexus block for upper limb surgeries increased the duration of sensory and motor blocks in comparison with the use of $0.5 \%$ bupivacaine, although the change was not statistically significant. Haghighi et al. ${ }^{(14)}$ observed that the effect of magnesium in the axillary brachial plexus block when applied to lidocaine in upper limb surgeries in contrast to the use of lidocaine alone, significantly increased the length of sensory and motor blocks. In Cairo, Egypt, Abdelfatah and Elshaer ${ }^{(12)}$ observed that the addition of magnesium sulphate to lidocaine in the interscalal brachial plexus block increased statistically significantly analgesic length and decreased postoperative pain and opioid requirements for shoulder arthroscopic acromioplasty. In Seoul, Korea, Lee et al. ${ }^{(16)}$ noted when applied to bupivacaine for interscalene brachial plexus block, magnesium sulphate induced a reduction in postoperative pain in arthroscopic rotator cuff repair.

We performed this study with a magnesium dose of $200 \mathrm{mg}$, but in previous studies, they used magnesium sulphate in doses of 150, 300, 450, and $600 \mathrm{mg}$.

Swami et al. ${ }^{(17)}$ noted that dexmedetomidine (1 $\mu \mathrm{g} / \mathrm{kg}$ ) plus local anaesthetic (35 cc, 0.25 percent bupivacaine) for supraclavicular brachial plexus block improved sensory and motor block length, as well as analgesia duration. In patients receiving dexmedetomidine, the time for rescue analgesia was extended. It also increased block consistency compared to clonidine $(1 \mu \mathrm{g} / \mathrm{kg})$. Zhang et al. ${ }^{(18)}$ also reported that there was prolonged sensory and motor blockade length in patients who obtained dexmedetomidine $(50 \mu \mathrm{g})$ in 40 $\mathrm{ml}$ of 0.33 percent ropivacaine compared to the control group for axillary brachial plexus blockade. However, dexmedetomidine was also followed by an increased occurrence of complications such as bradycardia, hypertension, and hypotension. In contrast to our study Elyazed and Mogahed ${ }^{\left({ }^{(19)}\right.}$ stated that $\mathrm{Mg}$ sulphate made the onset of block slower than block with local anesthetic alone when they used it as an additive to infraclavicular nerve block in comparison with dexmedetomidine.

In our study we found that both $\mathrm{Mg}$ sulphate (sensory duration $7.90 \pm 2.19$ hours) (motor block duration $8.50 \pm 2.33$ hours) and dexmedetomedine (sensory block duration $9.20 \pm 1.91$ hours) (motor duration $9.80 \pm 1.933$ hour) increased the duration of block and analgesia, but dexmedetomidine increased the duration more than $\mathrm{Mg}$ sulphate. Also, both dexmedetomidine and $\mathrm{Mg}$ sulphate delayed time of first analgesia requirement and also the total analgesic doses required than local anesthetic alone, but dexmedetomidine was better than $\mathrm{Mg}$ sulphate in this. In agreement with our study, El-Morabaa et al. ${ }^{(20)}$ found that $\mathrm{Mg}$ sulphate prolongs sensory block and analgesia with increasing the dose when added to local anesthesia perineurally when they compared between different groups with different dosses and routes of Mg Sulpahte. In accordance with our research Akhondzade et al. (21) reported that the addition of $\mathrm{Mg}$ sulphate to lidocaine reduced postoperative pain and increased the length of sensory and motor blocks in the supraclavicular brachial plexus block in upper limb surgery under ultrasound guidance.

Regarding first request analgesia given, there was a significant difference between the three study groups ( $\mathrm{P}$ $=0.0001)$. It was highly significant smaller in group $\mathrm{D}$ compared to group $\mathrm{C}(\mathrm{P} 2=0.0001) \&$ compared to group $\mathrm{M}$, it was mildly significant smaller $(\mathrm{P} 3=0.001)$, while there was mildly significant smaller in group $\mathrm{M}$ compared to group C $(\mathrm{P} 1=0.003)$.

Concerning total analgesic dose postoperatively, there was a moderately significant difference between the three study groups $(\mathrm{P}=0.001)$. It was moderately significant smaller in group $\mathrm{D}$ compared to group $\mathrm{C}(\mathrm{P}=$ $0.001)$ \& compared to group $M$, it was mildly significant smaller $(\mathrm{P}=0.032)$, while there was mildly significant smaller in group $\mathrm{M}$ compared to group $\mathrm{C}(\mathrm{P}=0.031)$. ELShamaa et al. ${ }^{(22)}$ found that diclofenac sodium (35.6 $\mathrm{mg}$ vs. $113.6 \mathrm{mg}$ ) was statistically substantially less as a rescue analgesic in the bupivacaine plus magnesium group, compared to bupivacaine plus regular saline group during the femoral nerve block. Other authors also found that less patients in the magnesium sulphate group requested rescue analgesia (9 vs. 30 ).

In our study as regards complication in comparison between three studied groups, only one patient of each group developed attack of nausea with or without vomiting managed by metoclopramide i.v., only one patient of group $\mathrm{C}$ developed transient attack of hypotension managed by ephedrine i.v. The incidence of complications and side effects were not affected by addition of $\mathrm{Mg}$ and a less significant difference at $18 \mathrm{hrs}$ postoperatively. In accordance with the research by Swami et al. ${ }^{(17)}$ and Esmaoglu et al. ${ }^{(23)}$, no major serious side effects were identified in any group in their study with the exception of lower pulse rates and blood pressure found in conservatively controlled dexmedetomidine groups.

\section{CONCLUSION}

In our study, we concluded that supraclavicular block is a safe technique and has many advantages. Our study demonstrated that both $\mathrm{Mg}$ sulphate and dexmedetomidine as additives for supraclavicular brachial plexus block hastens most of properties of block like onset of sensory block, motor block and provided a longer duration of motor blockade and postoperative analgesia as compared to control group in which patients received local anesthetic only. As comparison between $\mathrm{Mg}$ sulphate and dexmedetomidine, $\mathrm{Mg}$ sulphate as additive to local anesthetic in block made the onset of block faster than dexmedetomidine which made the onset even slower than block with local anesthetic alone. As regards duration of block, both $\mathrm{Mg}$ sulphate and 
dexmedetomidine increased duration of block than block with only local anesthetic but $\mathrm{Mg}$ sulphate made the duration longer than dexmedetomidine. As regards analgesia, both of them increased time of analgesia postoperatively but dexmedetomidine increased time of analgesia more than $\mathrm{Mg}$ sulphate. As regards complications and side effects, both of them as additive had no effect on incidence of complications or side effects of block.

\section{REFERENCES}

1. Sanford M, Keating G (2010): Levobupivacaine: A review of its use in regional anaesthesia and pain management. Drugs, 70: 761-91.

2. Bone H, Van Aken H, Brooke M et al. (2000): Enhancement of axillary brachial plexus block anaesthesia by coadministration of neostigmine. Reg Anesth Pain Med., 24 (5): 405-410.

3. McCloskey J, Haun S, Deshpande J (1992): Bupivacaine toxicity secondary to continuous caudal epidural infusion in children. Anesthesia and Analgesia, 75: 287-290.

4. Viel E, Eledjam J, de la Coussaye J et al. (1989): Brachial plexus block with opioids for postoperative pain relief: Comparison between buprenorphine and morphine. Reg Anesth., 14: 274-8.

5. Fletcher D, Kuhlman G, Samii K (1994): Addition of fentanyl to $1.5 \%$ lidocaine does not increase the success of axillary plexus block. Reg Anesth., 19: 183-8.

6. Shehabi Y, Ruettimann U, Adamson H et al. (2004): Dexmedetomidine infusion for more than 24 hours in critically ill patients: Sedative and cardiovascular effects. Intensive Care Med., 30: 2188-96.

7. El-Hennawy A, Abd-Elwahab A, Abd-Elmaksoud A et al. (2009): Addition of clonidine or dexmedetomidine to bupivacaine prolongs caudal analgesia in children. $\mathrm{Br} \mathrm{J}$ Anaesth., 103: 268-74.

8. Swami S, Keniya V, Ladi S et al. (2012): Comparison of dexmedetomidine and clonidine (a2 agonist drugs) as an adjuvant to local anaesthesia in supraclvicular brachial plexus block: A randomized double-blind prospective study. Indian J Anaesth., 56: 243-9.

9. Rao L, Jeyalakshmi V, Nagaraju M et al. (2015): The effect of magnesium sulfate as an adjuvant to $0.5 \%$ bupivacaine on motor and sensory supraclavicular brachial plexus blockade. Int J Basic Clin Pharmacol., 4 (2): 317-21.

10. Mukherjee K, Das A, Basunia S et al. (2014): Evaluation of Magnesium as an adjuvant in Ropivacaine-induced supraclavicular brachial plexus block: A prospective, doubleblinded randomized controlled study. J Res Pharm Pract., 3 (4): 123-9.
11. Gomide L, Ruzi R, Mandim B et al. (2018): Prospective study of ultrasound-guided peri-plexus interscalene block with continuous infusion catheter for arthroscopic rotator cuff repair and postoperative pain control. Rev Bras Ortop., 53 (6): 721-727.

12. Abdelfatah A, Elshaer A (2014): The effect of adding magnesium sulfate to lidocaine in an interscalene plexus block for shoulder arthroscopic acromioplasty. Ain-Shams J Anesthesiol., 7 (1) : 59-63.

13. Verma V, Rana S, Chaudhary S et al. (2017): A dosefinding randomised controlled trial of magnesium sulphate as an adjuvant in ultrasound-guided supraclavicular brachial plexus block. Indian J Anaesth., 61: 250-5.

14. Haghighi M, Soleymanha M, Sedighinejad A et al. (2015): The effect of magnesium sulfate on motor and sensory axillary plexus blockade. Anesth Pain Med., 5 (1): 21943.

15. Rao L, Jeyalakshmi V, Nagaraju M et al. (2015): The effect of magnesium sulfate as an adjuvant to $0.5 \%$ bupivacaine on motor and sensory supraclavicular brachial plexus blockade. Int J Basic Clin Pharmacol., 4 (2): 317-21.

16. Lee A, Yi H, Chung I et al. (2012): Magnesium added to bupivacaine prolongs the duration of analgesia after interscalene nerve block. Can J Anaesth., 59 (1) : 21 -7.

17. Swami S, Keniya V, Ladi S et al. (2012): Comparison of dexmedetomidine and clonidine (a2 agonist drugs) as an adjuvant to local anaesthesia in supraclvicular brachial plexus block: A randomized double-blind prospective study. Indian J Anaesth., 56: 243-9.

18. Zhang Y, Wang C, Shi J et al. (2014): Perineural administration of dexmedetomidine in combination with ropivacaine prolongs axillary brachial plexus block. Int J Clin Exp Med., 7: 680-5.

19. Elyazed M, Mogahed M (2018): Comparison of Magnesium Sulfate and Dexmedetomidine as an Adjuvant to $0.5 \%$ Ropivacaine in Infraclavicular Brachial Plexus Block. Anesthesia Essays and Researches, 12 (1): 109-115.

20. El-Morabaa I, Mamdouh A, Sayed M (2018): Comparison between 3 Different Doses of Magnesium Sulphate as A Spinal Adjuvant to Bupivacaine and Fentanyl Combination in Lower Limb Orthopedic Surgery. Med J Cairo Univ., 86 (6): 3253-3262.

21. Akhondzade R, Nesioonpour S, Gousheh M et al. (2017): The Effect of Magnesium Sulfate on Postoperative Pain in Upper Limb Surgeries by Supraclavicular Block Under Ultrasound Guidance. Anesth Pain Med., 7 (3): 14232.

22. ELShamaa H, Ibrahim M, Eldesuky H (2014): Magnesium sulfate in femoral nerve block, does postoperative analgesia differ? A comparative study. Egypt J Anaesth., 30: 169-73.

23. Esmaoglu A, Mizrak A, Akin A et al. (2005): Addition of dexmedetomidine to lidocaine for intravenous regional anaesthesia. Eur J Anaesthesiol., 22: 447-51. 